\title{
Tweeting To Learn: Understanding Twitter through the Lens of Connectivism
}

\author{
Nirupama Akella, MS \\ Instructional Designer \\ Georgia Military College
}

Twitter, primarily a social media outlet, has recently started foraying and gaining a foothold in higher education. Written from a student perspective, this paper attempts to explain and critically discuss the usage and popularity of Twitter as a tool of active learning in higher education. The author writes about her student experience of using Twitter in her Public Relations Communications graduate class. The paper explores and scrutinizes the social media channel within the theoretical framework of connectivism.

Twitter appeared on the contemporary education scene in late October 2006. Originally developed as a social messaging microblogging tool, Twitter found its way into higher education institutions (Grosseck \& Holotescu, 2008). At present, a growing number of higher educational institutions all over the world are teaching courses through this microblogging social media application. Twitter is a microblogging tool which allows users to send brief but informative messages to each other in fewer than 140 characters (Grosseck \& Holotescu, 2008). The messages are called tweets, the people who tweet are called twitterers, and the people who read these tweets and respond to them are called users. It allows for real-time communication, diverse interaction, discussion with collaboration, and sharing of experiences and opinions (Skiba, 2008). Twitter has become a popular teaching tool that provides for active learning, learner attention, learner discovery, learner participation, and learner knowledge schema development.

Written from a graduate student's viewpoint, this paper examines and discusses the usage of the educational technological tool of Twitter in the classroom. The author writes in depth about her experience and observation of using Twitter in her graduate Public Relations class at an international university in south-east USA. She explains the role and usage of Twitter using the contemporary online learning theory of connectivism. The paper is divided into three sections. Section One provides a brief explanation of connectivism theory, followed by the author's story in Section Two. The third and final section of the paper embodies the discussion where the connectivism theory is revisited in greater depth. Through her paper, the author hopes to generate relevant and meaningful debate about using Twitter as a method of student engagement in graduate classrooms.

\section{What is Connectivism?}

Connectivism, the learning theory of the digital online age, focuses on and emphasizes 'social and experience learning' (Siemens, 2005). The gist of the theory states that people learn through connections of social and cultural interaction, and experience (Siemens, 2005). Each individual is a potential source of information and knowledge which has been developed through social observation and learning. This knowledge within the individual forms a mental framework, or schemata. Thus, a schemata or schema is a mental open framework of knowledge. Every single source of knowledge, in connectivist terms, is a 'node' that has already developed a schema. The node interacts with another node and then another to form a network. This network then becomes a channel of interaction wherein opinions, experiences, and factual information are shared. Hence, nodes develop a holistic schemata through these connections (Siemens, 2005). A network of connections becomes a method of knowledge-building. In the following section the author details her factual story of how Twitter was utilized in her graduate class. 


\section{My Story}

"What are you doing?"

This used to be the constant query and response I had become used to in my Public Relations class CA 511 in Fall 2009. This was a graduate elective offered in the master's degree program of Communication. Besides me, there were nine other graduate students, all from the same program, but with different majors such as Broadcasting, Digital Media, Media Research Methods, Organizational Corporate Communication, and Advertising. I myself had the major of Organizational Corporate Communication. The Public Relations class was scheduled to run for 12 weeks, with weekly assignments on chapter topics, a midterm and final exam, and a small group presentation on a real-time public relations campaign. The class, being small with only ten students, had been divided into five groups with two students each. The class had two textbooks and many class readings to be given by the instructor in class.

The first sign that this class was not going to be the traditional classroom lecture one came with the announcement on the course website. The instructor announced that the entire course would be taught via Twitter. The class would meet every week on Thursday and discuss their tweets. Thus, every week, our twitter session was to revolve around a chapter and issues related to it. The instructor would post the first tweet, initiating and directing the class discussion. This first tweet was followed by responses throughout the week. The discussion would close on Thursday and a weekly assignment would be handed out to all the students. In total there were 14 topics and this meant 14 class discussions in a period of 12 weeks.

I had used Twitter earlier for social messaging but this was to be the first time I was going to use it for class. I was excited, and also nervous. There was no one to point the finger at and say, "The instructor failed to tell me." I could only point the finger at myself if I did not understand, and failed to clarify issues with my fellow classmates on Twitter. Each class member was given instructions during first day of class on opening twitter accounts and the discussion process. Twitter's avatar feature helped in viewing headshots of every class member's avatar. This helped in humanizing the twitter discussion system, making it personal and realtime. The instructor's tweet had a question, an opinion supported by relevant research facts. Tweets had to be concise and precise, as each tweet had a limited character count of 140 . The followers, i.e., each student, had to answer the primary tweet with an answer and personal opinion, or observation. This tweet was answered by a fellow twitterer and so forth. The discussion ended on the Thursday with a summative tweet posted by the instructor before the face-to-face class. During the one-hour afternoon class, main points of the topic were discussed, followed usually by a quiz and a hand-out of the weekly assignment. The completed assignment was to be submitted during the next face-to-face class. Discussions, weekly assignments, and quizzes were to be part of the final grade.

In the beginning, specifically the first three weeks, none of us in the class could really learn anything on Twitter. During the first two weeks' discussions, most of my classmates tweeted "how does this work?"-“is this serious?" Each avatar would reply to primary tweet and that was the end of the class discussion. The system was used to chat about movies and fashion. Although the curriculum covered topics of definition, history, technology of public relations, discussions on twitter were frivolous. After three weeks of frivolous tweeting and silent discussions, I was sure the instructor would give up this idea of conducting class on Twitter.

But class demeanor underwent a change after the midterm. The entire class did badly, with everyone scoring an average $\mathrm{C}$ grade. I was sure that after this dismal performance, the instructor would cancel the class on Twitter. The instructor tweeted a few more instructions and warnings. I did not want a bad academic grade in my Public Relations class to negatively impact my GPA. I genuinely started making a positive effort in tweeting my opinions and questions. I 
began tweeting seriously, and so did my classmates. Class discussions now became intense, challenging, and a place to test our knowledge and facts. Soon the class had formed a learning network, where each one of us was tweeting a chunk of information. This enabled the class to form their own mental schema through active assimilation and accommodation. The instructor had created a real-time class chatter session and space which provided the class with the opportunity to relate real-life public relations issues with chapter topics. The instructor was part of this chatter, allowing him to maintain control over what was happening. For instance, in week eight the class studied the topic of corporate social responsibility. After going through the text and the book questions, I had formed my own opinion about corporate social responsibility. I immediately tweeted the factual information with my own opinion to fellow-followers. My tweet got many responses, which made me research more into the topic. A tweet about the Enron scandal made me search articles and read about it. The class discussion became exciting and informative. I soon discovered that each one of us was more just a 'twitterer' or 'follower'. Every one of my classmates, including myself and the instructor, was a source of knowledge and information. We were learning from each other's observations, opinions, experiences, and observations. My instructor tweeted about the Bhopal Gas tragedy, and the next day my classmates and I were tweeting about it. At the end of the week, the discussion had become argumentative and combative. The final tweet by the instructor summarized the entire class discussion, congratulating each twitterer on their active participation.

My original schemas on various topics formed from textbook knowledge now accommodated knowledge gathered from my network of twitterers. This helped me to develop a holistic schema on each topic, and ultimately perform well in my quizzes and weekly assignments. The last topic covered in the course, just before the final, became a fun activity due to Twitter. This was on contemporary issues of Public Relations. Discussing this on Twitter was interesting, as every one of us had a different opinion and was constantly challenging every tweet. The class network explored, critically reflected on and scrutinized issues faced by public relations practitioners, and the future of public relations. Some tweets linked current challenges with past issues, and other academic disciplines. Twitter 'connected' us and formed a close-knit network of learners. Finals came and the class scored an average of B grade.

\section{Discussion}

Why did Twitter work? Twitter is effective in contemporary education, as it follows the principle that learning and knowledge are not static artifacts but processes whereby learners can develop their own mental construction of the truth, or knowledge (Jarche, 2011). Usually, what happens in the traditional classroom is that learners echo and assimilate the opinion and attitude of the expert, i.e., the instructor. There is no room for critical self-thinking and development of individual schema (Seimens, Cormier, \& Downes, 2011). The social media of Twitter is based on the theory of connectivism, which holds that every learner is a contributor to the learning process. Connectivism advocates that every learner is a node of minute knowledge. These nodes form powerful networks of learning when the nodes connect and share information with each other (Seimens et al., 2011). Twitter functions on the primary principles of connectivism that knowledge is a dynamic process of growth, which seems to abound when people (nodes) connect and create 
a network. Thus, connectivism resembles the theory of social constructivism (Kop, 2011). Social constructivism argues that learning and knowledge are steeped in communication, sharing, and dialogue. Seimens believes that this is a cardinal feature of connectivism (Seimens, 2005). Learning and knowledge grow and deepen through a diversity of opinions and beliefs. It is paramount to connect and share information and truth, as capacity to know and understand what is happening in the real world is more critical than what is known through books (Seimens, 2005).

This is what happened in my public relations class. The instructor forced each one of us to connect and share our opinions and current information. The traditional classroom now had become an online learning community. And the main node of this community, or in connectivist terms, this network was the instructor. Every week, the instructor would post a tweet capturing the main ideas of the chapter to be covered in the class that week. This tweet was a guide post, shaping the rest of our chatter. In other words, it was the responsibility of the instructor to post a "nugget of knowledge" every week and ensure communication, collaboration, and dialogue (Skiba, 2008). This sort of sharing and communicating with each other informally without formal class pressures, I think, helped us to overcome fear of speaking up in class in front of everyone. Each one of us was just tweeting and chatting about that particular topic-what we thought, current examples, and controversies. It enabled us to form our own mental constructions of that topic and critically reflect about it. For instance the corporate social responsibility of organizations and the role of public relations was a huge topic in the course, and the instructor devoted two weeks to it. He followed a similar pattern, posting the main idea and encouraging the class to discuss about it. I read the chapter, made notes and started tweeting in the class chatter space. After the first 25 tweets on textual facts and figures, the conversation moved on to examples. Twitterers discussed, argued, and debated about role of public relations during the Bhopal Gas Tragedy in the 1980s; during the Enron scandal in the 1990s, and the political role of public relations. All these discussions enabled me to broaden and deepen my narrow and limited schema at a more holistic level. It helped me to engage in deeper learning, where I was able to identify the common points and main similarities of diverse events and make connections to form a holistic open schema. This falls in line with what Garrison and colleagues state, that Twitter helps in deep learning (Garrison, Andersen, \& Archer, 2000).

Twitter successfully allows for assimilation and accommodation of knowledge, and also metacognition. It enables learners to reflect on their thoughts and thinking process to concisely formulate tweets (Educause, 2007). Tweeting enables learner to critically reflect on what they are thinking-- it encourages them to discuss their opinions and thoughts without hesitancy, and make suitable modifications to their thoughts (Carnevale, 2006). Hence, the learner learns through processes of assimilation, accommodation, metacognition, collaboration, and active learning. Twitter makes the entire cycle of learning student or learnercentric, where the learner is in charge. Another facet of Twitter is its ability to help the learner see and understand the bigger picture, i.e., how facts and issues do not exist in isolation but belong to a larger scheme of issues. For instance, corporate social responsibility is an integral part of public relations which ties into advertising, organizational behavior, human resources development and management, industrial relations, and ethics.

But the success of twitter is largely dependent on the role and motivation of the learner (Kop, 2011). In the public relations class, Twitter failed to make headway during the first few weeks of class. Why? None of the students were motivated to use the Twitter as a tool for learning. I had always viewed the Twitter as a social media tool, fit only for social communication. Using it for learning purposes was new and not serious. I was sure my instructor would soon realize his folly and disband use of Twitter as the medium of learning by switching back to the traditional classroom lecture method of education. This method was safe and did not actually require me to think and be on my mental feet all the time. In other 
words, it did not require active learning at all. But the results of the midterm changed the entire attitude of my classmates, including myself, in a big, visible way. I started tweeting seriously-discussing facts, topics, and issues. Twitter enabled me to answer all my essay questions in the final and score an A grade. This happened, as Kop explains, because each one of us changed our attitudes and motivations. Take me, for instance-earlier, I never did take Twitter seriously, never made the effort as my motivation level was low. I was waiting for the instructor to revert back to the lecture mode of teaching. But the midterm results gave the boost to my motivation. I realized that I had to change my attitude. Twitter was going to remain and was not going away. So I had to change my mindset and my motivation. Thus, I started learning when I changed my attitude and my motivation level went up.

Kop argues that each learner has to don the mantle of individual learning and schema development. The instructor is no longer the know-it-all model of knowledge, and is not responsible for the learner's level and amount of learning (Kop, 2011). Learning is now resident in the connections individual learners establish and nurture (Seimens, 2005). This means that every individual learner has to be a fully committed and responsible adult learner. Again, going back to my example, Twitter became a useful and successful medium of

Twitter helped me, as a student, to develop a critical mode of thought and holistic perspective. I no longer saw the instructor as the ultimate source of knowledge.

learning when each one of us became a responsible adult learner. When this happens, Twitter engages the entire community with the three facets of learning, i.e., cognitive, social, and teaching presence. Twitter helps the learner to think on his and her own, enables learners to interact in an informal learning community, and the teacher's presence is existent, as even the instructor is another node of information in the community (Garrison et al., 2000).

Twitter helped me, as a student, to develop a critical mode of thought and holistic perspective. I no longer saw the instructor as the ultimate source of knowledge. Rather, my classmates, the instructor, and I had minute bits of knowledge. These tiny chunks were shared by all of us (nodes) to form a learning network which developed a holistic mental representation of the 'truth.' This truth was subjective and had individual ownership. Each one us individual nodes owned this schema and felt responsible for it.

\section{Conclusion}

In contemporary higher education, learning is viewed as a process that is constantly growing and developing. The use of Twitter to benefit from this perspective has changed the manner in which curricula, instruction, and instructors are viewed. Instructors have to embrace the role of mentor, guide, and coach, who have to guide the learning process. Twitter has increased the role and importance of instructional design as a professional specialized field. Instruction and curriculum have to be designed to prompt and encourage active critical reflection, communitybuilding, collaboration, and formal as well as informal interactions.

This paper provides only a small insight into the world of Twitter in higher education. Specifically, it details a student's experience of using Twitter in a graduate humanities class. Research has to be conducted which shows the teacher's perspective and argument. What do instructors believe and feel? How do they view Twitter within the theoretical framework of connectivism as a viable tool of education? Can Twitter be viewed as a viable method of student engagement in quantitative courses of math and science? These are pertinent research questions which can develop into interesting research areas. 


\section{References}

Carnevale, D. (2006). E-mail is for old people. Chronicle of Higher Education, 53(7), A27-A29.

Educause Learning I nitiative. (2007). 7 things you should know about Twitter. Retrieved from www.educause.edu/ir/library/pdf/ELI 7027.pdf

Garrison, D. R., Anderson, T., \& Archer, W. (2000). Critical inquiry in a textbased environment: Computer conferencing in higher education. The Internet and Higher Education, 2(2-3), 87-105.

Grosseck, G., \& Holotescu, C. (2008). Can we use Twitter for Educational Activities? In 4th international scientific conference, eLearning and software for education, Bucharest, Romania.

Jarche, H. (2011). Personal knowledge management. Information Outlook, 14(6), 13-15.
Kop, R. (2011). The challenges to connectivist learning on open online networks: Learning experiences

during a massive open online course. The International Review of Research in Open and Distance Learning, 12(3), 19-38.

Seimens, G. (2005). Connectivism: A learning theory for the digital age. International J ournal of Instructional Technology and Distance Learning,

2(1). Retrieved from: http://www.itdl.org/J ournal/J an_05/a rticle01.htm

Seimens, G., Cormier, D., \& Downes, S. (2011). Change MOOC. Retrieved from:

http:///change.mooc.ca/about.htm

Skiba, D. J. (2008). Nursing Education 2.0: Twitter \& Tweets- Can you post a nugget of knowledge in 140 Characters or less? Emerging Technologies, 29(2), 110-113.

Nirupama Akella is a qualified instructional designer at the Georgia Military College, Milledgeville, Georgia. Resident in Milledgeville, Nirupama's research interests include but are not limited to adult learning, pedagogy, instructional design and curriculum development. Nirupama Akella is also an accomplished published poet, fiction writer, and novelist. 